\section{Hospital Costs in Patients with Nosocomial Methicillin-Resistant or Methicillin- Susceptible Staphylococcus aureus Bloodstream Infection}

To the editor.-Given our interest in health economics in the field of infectious disease research, we read with interest the article by Dr Ben-David and colleagues published in the May 2009 issue of the journal. ${ }^{1-5}$ The authors examined the attributable impact of methicillin resistance among patients with nosocomial methicillin-resistant Staphylococcus aureus bloodstream infection on hospital mortality, length of stay, and costs, compared with patients with nosocomial methicillin-susceptible $S$. aureus bloodstream infection. Their initial results suggested increased resource use in terms of hospital costs and length of stay associated with methicillin resistance; however, after they had accounted for potential confounders by means of a propensity score analysis, their final results did not reveal increased resource use. ${ }^{3}$

Although we agree with the conclusion of Dr Ben-David and colleagues, we have some suggestions regarding the additional study that they propose. In their propensity score, which was assessed for each individual case patient, the authors did not include prior use of antibiotic agents (appropriateness of therapy, number of antibiotics administered, and duration of antibiotic use) and whether the patients were cared for in a long-term care facility prior to hospital admission-both variables that are associated with acquisition of antibiotic resistance. ${ }^{6-8}$ As such, important bias may remain, because the propensity score adjusted for in their analysis may not satisfactorily correct for existing differences between patients with nosocomial bloodstream infection caused by methicillin-resistant $S$. aureus and patients with nosocomial bloodstream infection caused by methicillin-susceptible S. aureus. ${ }^{9}$ In an aim to increase the generalizability of a propensity score to other settings or institutions, however, it is important to keep such a "probability model" as simple as possible, which means retaining only the most clinically relevant variables in the final analysis. In this regard, we do not completely comprehend why some characteristics that seem not to have any relationship to methicillin resistance were included (eg, presence of cirrhosis or diabetes mellitus $[P=$ .7]; see their Table 4), while other characteristics were excluded (eg, residence in a long-term care facility), even though they were statistically and clinically relevant. We would like to kindly invite Dr Ben-David and colleagues to clarify the decision process by which potential confounders were included or excluded from the final model on which the propensity score was based.

\section{ACKNOWLEDGMENTS}

Financial support. S.I.B. is supported by a grant from the European Society of Intensive Care Medicine and iMDsoft Patient Safety Research Award 2008.

Potential conflicts of interest. All authors report no conflicts of interest relevant to this article.

\section{Dominique M. Vandijck, $\mathrm{PhD}$; Lieven Annemans, $\mathrm{PhD}$; Dirk P. Vogelaers, PhD; Stijn I. Blot, $\mathrm{PhD}$}

From the Department of Public Health and Health Economy, Ghent University (D.M.V., L.A.), the Department of General Internal Medicine and Infectious Diseases, Ghent University Hospital (D.M.V., D.P.V., S.I.B.), and the Department of Healthcare, University College Ghent (D.P.V., S.I.B.), Ghent, Belgium.

Address reprint requests to Dominique $\mathrm{M}$. Vandijck, $\mathrm{PhD}$, Faculty of Medicine and Health Sciences, Department of Public Health and Health Economy, Ghent University, De Pintelaan 185, 9000 Ghent, Belgium (dominique.vandijck@ugent.be).

Infect Control Hosp Epidemiol 2009; 30:1127

(C) 2009 by The Society for Healthcare Epidemiology of America. All rights reserved. 0899-823X/2009/3011-0017\$15.00. DOI: 10.1086/647984

\section{REFERENCES}

1. Vandijck DM, Blot SI, Decruyenaere JM, et al. Costs and length of stay associated with antimicrobial resistance in acute kidney injury patients with bloodstream infection. Acta Clin Belg 2008; 63:31-38.

2. Vandijck DM, Depaemelaere M, Labeau SO, et al. Daily cost of antimicrobial therapy in patients with intensive care unit-acquired, laboratory-confirmed bloodstream infection. Int I Antimicrob Agents 2008; 31:161-165.

3. Ben-David D, Novikov I, Mermel LA. Are there differences in hospital cost between patients with nosocomial methicillin-resistant Staphylococcus aureus bloodstream infection and those with methicillin-susceptible S. aureusbloodstream infection? Infect Control Hosp Epidemiol 2009; 30:453-460.

4. Depuydt PO, Vandijck DM, Bekaert MA, et al. Determinants and impact of multidrug antibiotic resistance in pathogens causing ventilator-associated-pneumonia. Crit Care 2008; 12:R142. http://ccforum.com/content/ 12/6/R142. Published November 17, 2008. Accessed November 17, 2008.

5. Vandijck DM, Blot SI, Labeau SO, et al. Candidemia in critically ill patients: an analysis of daily antifungal therapy related costs. J Mycol Med 2008; 18:96-99.

6. Shurland SM, Stine OC, Venezia RA, et al. Colonization sites of USA300 methicillin-resistant Staphylococcus aureus in residents of extended care facilities. Infect Control Hosp Epidemiol 2009; 30:313-318.

7. Hoste EA, Vandijck DM, Van Holder RC, et al. Health implications of antimicrobial resistance for patients with acute kidney injury and bloodstream infection. Infect Control Hosp Epidemiol 2007; 28:1107-1110.

8. Iosifidis E, Antachopoulos C, Tsivitanidou M, et al. Differential correlation between rates of antimicrobial drug consumption and prevalence of antimicrobial resistance in a tertiary care hospital in Greece. Infect Control Hosp Epidemiol 2008; 29:615-622.

9. Blot S, Depuydt P, Vandewoude K, De Bacquer D. Measuring the impact of multidrug resistance in nosocomial infection. Curr Opin Infect Dis 2007; 20:391-396. 